\title{
Effectiveness of sofosbuvir/pegylated-interferon plus ribavirin in treatment of hepatitis $C$ virus genotype 4 patients
}

\author{
Adel Abdel-Moneim', Alaa Abood², Mohamed Abdel-Gabaar, Mohamed I. Zanaty4', Mohamed Ramadan ${ }^{3}$ \\ ${ }^{1}$ Molecular Physiology Division, Faculty of Science, Beni-Suef University, Egypt \\ ${ }^{2}$ Tropical Medicine Department, Faculty of Medicine, Beni-Suef University, Egypt \\ ${ }^{3}$ Biochemistry Division, Chemistry Department, Faculty of Science, Beni-Suef University, Egypt \\ ${ }^{4}$ Biotechnology Department, Postgraduate Studies for Advanced Science, Beni-Suef University, Egypt
}

\begin{abstract}
Introduction: New regimens involving direct-acting antiviral agents (DAAs) have recently been approved for the treatment of hepatitis $C$ virus (HCV) genotype 4 (GT4). The current study aims to assess the efficacy and safety of sofosbuvir (SOF) with pegylated interferon (PegINF)/ribavirin (RBV) for chronic HCV GT4 patients at the beginning of the interferon-free era.

Material and methods: Between March 2015 and November 2015, 99 patients (59 naïve and 40 experienced) infected with HCV GT4 were enrolled in the study. Eligible patients received daily oral $400 \mathrm{mg} \mathrm{SOF,} \mathrm{RBV} \mathrm{(body}$ weight: $<75 \mathrm{~kg}, 1000 \mathrm{mg} ;<75 \mathrm{~kg}, 1200 \mathrm{mg}$ ), the dose modified according to patient tolerability, plus $180 \mu \mathrm{g}$ PegINF $\alpha$-2 once weekly for 12 weeks.

Results: Among the patient cohort, sustained virological response 12 weeks after the end of treatment (SVR12) was achieved by $88 \%(87 / 99)$ of all patients, by $93 \%$ (55/59) of naive patients and by $80 \%(32 / 40)$ of experienced patients. Regarding treatment failure, the data recorded 12\% (12/99) of patients (4 null responses and 8 relapsers). Otherwise, the most common adverse events observed during the study included headache, nausea, fatigue, dyspnea, influenza-like illness, anemia, and leukopenia.

Conclusions: SOF combination-based therapies were considered promising choice regimens for chronic HCV infection. The present findings suggest that the combination of the SOF/PegINF/RBV regimen was effective for Egyptian patients with HCV GT4. The recorded adverse events and viral outcome revealed the high need for further efforts to minimize the side effects of the current regimen and/or replace PegINF with additional potent DAA(s) to increase SVR12 to achieve $100 \%$.
\end{abstract}

Key words: HCV genotype 4, sofosbuvir, Peg-interferon $\alpha-2$, ribavirin, Egyptian patients.

Address for correspondence

Adel Abdel-Moneim, Molecular Physiology Division, Beni-Suef University, Salah Salim St., 62511, Beni-Suef, Egypt, phone: +2 01006 5451764, fax: +2 082233 4551, e-mail: adel_men2020@yahoo.com; adel.hassan@science.bsu.edu.eg

\section{Introduction}

The hepatitis $\mathrm{C}$ virus (HCV) and its long-term complications are a major medical health problem in the world and Egypt. More recent epidemiological studies in Egypt have an estimate of $7.3 \%$ of the population with viremic HCV in 2013 [1]. HCV genotype 4 (GT4) has been considered in several studies as "diffi- cult to treat" with classical hepatic regimens, pegylated interferon (PegINF) and ribavirin (RBV) [2].

Up to the end of 2013, the only treatment option for HCV GT4 was treatment with PegINFa with RBV for 24-48 weeks. In the past few years, new treatment regimens have been developed that are high in sustained virological response (SVR) rates, well tolerated, short in treatment duration and offer new opportunities 
for previously excluded groups [3]. Sofosbuvir (SOF) (Gilead Sciences, Inc., USA), is an oral NS5B nucleotide polymerase inhibitor with potential therapeutic efficacy in HCV patients with GT1-6 [4, 5]. Furthermore, SOF for the treatment of HCV GT4 promises marked amelioration in the virological outcome of therapy [4] and it is considered an excellent backbone for combination direct-acting antiviral drug (DAA) regimens [6]. Additionally, SOF has a favorable safety profile, and most adverse reactions reported in clinical studies with SOF have been attributed to the use of RBV or PegINF [7].

Triple therapy, using a combination of PegINFa-2, $\mathrm{RBV}$, and/or potent DAA-based regimens, result in HCV eradication in the majority of patients infected with chronic HCV [8]. Six regimen options were available in 2015 for patients with HCVGT4 infection including two INF-containing regimens and four INFfree regimens [9]. Furthermore, the addition of SOF with PegINF and RBV in genotypes 1, 4 and 6 increases the SVR rate with 12 -week duration of therapy (SVR12) [10]. Furthermore, Elsharkawy et al. [11] reported that treatment of Egyptian patients with both SOF/PegINF/RBV and SOF/RBV regimens achieved SVR rates of $94 \%$ and $78.7 \%$, respectively.

Most trials have been conducted in HCV GT1, but efficacy and safety data regarding DAA regimens in HCV GT4 patients are currently limited. The present study aimed to evaluate the efficacy and safety of SOF in combination with a classical regimen of PegINF/ RBV in Egyptian chronic HCV GT4.

\section{Material and methods}

\section{Study patients}

This study was conducted in three of the National Treatment Centers. A total of 104 patients, treatment-

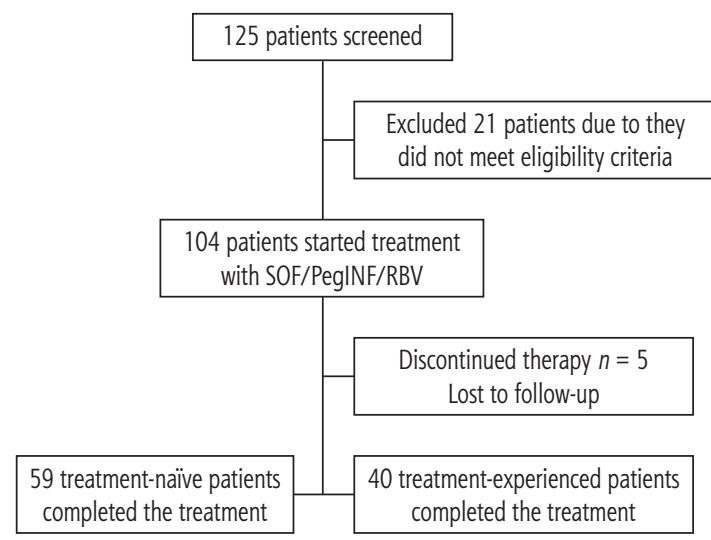

Fig. 1. Study flowchart naïve and treatment-experienced adults with chronic $\mathrm{HCV}$, started treatment under the Egyptian National HCV Control Program, but only 99 patients completed the study. Between March 2015 and November 2015, enrolled patients started and completed the treatment period. Written acceptance was obtained from all patients and the ethical committee approved the study protocol, which conformed to Egyptian National Guidelines and was performed in conformity with the Declaration of Helsinki and Good Clinical Practice guidelines (decision date: 5 February 2015).

The study population consisted of treatment-naïve and treatment-experienced adults patients aged 20-65 with HCV RNA level > 10,000 IU/ml. Experienced patients included patients with a prior relapse or a null response to PegINF/RBV therapy. Patients were excluded if they had been HCV coinfected with hepatitis B virus (HBV) or human immunodeficiency virus (HIV) or had any liver disease other than chronic HCV GT4 infection. Also, patients were excluded if they had a history of liver decompensation, serum a-fetoprotein (AFP) > $100 \mathrm{ng} / \mathrm{ml}$, evidence of hepatocellular carcinoma, major severe illness such as respiratory, renal and heart failure or autoimmune disease or non-compliance with treatment.

\section{Study design and treatment}

The patients were treated with one tablet of $400 \mathrm{mg}$ SOF (Sovaldi, Gilead Sciences, Inc., USA) and oral tablets of RBV (Copegus, Roche, Europe) based on body weight: $<75 \mathrm{~kg}, 1000 \mathrm{mg} ;<75 \mathrm{~kg}, 1200 \mathrm{mg}$ and modified according to patient tolerability, plus $180 \mu \mathrm{g}$ PegINFa-2 (Pegasys, Roche, Europe) given via subcutaneous injection once weekly. The endpoint was SVR12 defined as HCV RNA $<15 \mathrm{IU} / \mathrm{ml}$ undetectable at the actual end of treatment (EOT) of 12 weeks and HCV RNA undetectable 12 weeks after planned EOT. Viral relapse was HCV RNA undetectable at EOT, but detectable HCV RNA > $15 \mathrm{IU} / \mathrm{ml}$ levels 12 weeks after planned EOT. Data were collected at three time points: (1) baseline (before initiating therapy); (2) at end of treatment (EOT) (12 weeks) and (3) 12 weeks after the treatment cessation (SVR12) (Figure 1).

\section{Assessment of safety}

Adverse events (AEs) were assessed by the monitoring of AEs reported by clinical and laboratory test results. Additionally, laboratory chemical and hematological abnormalities were graded according to $\mathrm{WHO}$ criteria. 


\section{Laboratory assessment}

All eligible patients underwent clinical examinations before treatment, after 12 weeks of the therapy period (EOT), and also 12 weeks after the therapy cessation. The patients underwent laboratory investigation including aspartate aminotransferase (AST), alanine aminotransferase (ALT), albumin content and total bilirubin, determined using reagent kits purchased from Human Diagnostics (Germany). The FIB-4 score was calculated using Sterling's formula [12]. Interleukin-28B (IL-28B) genotype was estimated by use of polymerase-chain-reaction amplification (PCR), while HCV GT4 genotype was assessed by the VERSANT-HCV Genotype 2.0 Assay (LiPA) (Siemens, Germany). Quantitative polymerase chain reaction (qPCR) for HCV was assessed by Roche Amplicor HCV monitor version 2.0 (Roche Diagnostics, Branchburg, NJ), with lower detection limit < $15 \mathrm{IU} / \mathrm{ml}$. However, hematological parameters were determined using an auto-analyzer (MICROS $\mathrm{ABX}$ ) according to the manufacturer's protocol.

\section{Statistical analysis}

Data are expressed as mean \pm SEM. Data were analyzed using Student's $t$-test by Statistical Package for Social Science (SPSS) version 20 software. The virologic response was based on "modified intention to treat" analyses (mITT) or per-protocol analysis (only patients who complete the entire clinical study according to the protocol are counted towards the final results). Values with $p<0.05$ were considered significant.

\section{Results}

\section{Patients' characteristics}

A total of 125 patients were screened in some of the National Treatment Centers. However, 21 patients were excluded because they did not meet eligibility criteria. From 104 patients who started treatment, only 99 patients completed the treatment period. Experienced patients who received prior HCV treatments with PegINF/RBV numbered 40 subjects. Fibrosis was determined on the basis of the liver biopsy and/ or FIB-4 test in all of the patients; $13 \%$ had advanced fibrosis (F3-4) at baseline. All eligible patients except five patients (lost to follow-up) completed the study period (Figure 1), three patients had serious AEs related to PegINF therapy (hospitalized due to severe anemia with leukopenia and abdominal troubles) and there were no deaths or discontinuations recorded due to serious adverse events.

\section{Antiviral response (efficacy) and laboratory and safety assessment}

The treatment with SOF/PegINF/RBV regimen was effective and achieved a high virologic response in Egyptian patients with HCV GT4. Overall, SVR12 was achieved by $88 \%$ (87/99), by $93 \%$ (55/59) of naïve patients and by $80 \%(32 / 40)$ of experienced patients. Regarding treatment failure, 4 null responses and 8 relapses were observed (Table 1). Serum ALT and AST showed significantly decreased activities after treatment with the current therapy. Hemoglobin content and red blood cells (RBCs), leukocytes (WBCs), and platelet counts revealed significant decreases as compared to baseline values (Table 1).

The most common adverse events reported in the current study were headache, insomnia, nausea, dyspnea, and fatigue (Table 2). Also, influenza-like symptoms, rash and irritability were characteristic of the PegINF treatment group. Decreased hemoglobin (anemia) (40/99), and leukopenia (32/99) were more common laboratory abnormalities among patients receiving SOF/PegINF/RBV. Also, three patients had serious adverse events related to PegINF therapy (severe anemia, leukopenia, and abdominal troubles).

\section{Discussion}

The goal of the HCV regimen is to achieve an SVR, defined as continuously undetectable HCV RNA levels 12 weeks (SVR12) or 24 weeks (SVR24) after the end of therapy. In Egypt, the PegINF/RBV regimen was introduced through the National Treatment Program for chronic HCV patients. Since 2006, the SVR rates have ranged from $54 \%$ to $59 \%$ [13]. The discovery of DAA is an outstanding achievement of modern medicine in the current century and the approval of SOF by the FDA represents a new landscape in the management of HCV, especially GT4 infection.

In the present study, among patients treated with SOF/PegINF/RBV, SVR 12 was achieved by $88 \%$ of overall patients (naïve; 93\%, experience; $80 \%$ ). Our results in the present study were in concordance with previous studies evaluating treatment of in chronic HCV patients with SOF/PegINF/RBV therapy $[4,10$, $11,14]$. Furthermore, in the present study, significant improvement in activities of liver enzymes ALT and AST were recorded after treatment, confirming the beneficial effects of the treatment regimens.

The European Association for the Study of the Liver [9] issued 6 guidelines for HCV GT4 treatment and the first recommendation was to use PegINF/RBV with SOF for 12 weeks. SOF plus PegINF/RBV for 12 weeks 
Table 1. Demographics, laboratory abnormalities and virologic response of patients receiving sofosbuvir plus pegylated-interferon/ribavirin for 12 weeks

\begin{tabular}{|c|c|c|c|c|c|c|}
\hline Parameters & $\begin{array}{c}\text { Overall } \\
\text { baseline (99) }\end{array}$ & $\begin{array}{l}\text { Overall } \\
\text { SVR12 }\end{array}$ & $\begin{array}{c}\text { Naïve } \\
\text { baseline (59) }\end{array}$ & $\begin{array}{l}\text { Naïve } \\
\text { SVR12 }\end{array}$ & $\begin{array}{c}\text { Experienced } \\
\text { baseline (40) }\end{array}$ & $\begin{array}{l}\text { Experienced } \\
\text { SVR12 }\end{array}$ \\
\hline Age, years & 48.56 & & 47.46 & & 47.2 & \\
\hline Mean (SD) & 9.73 & & 9.65 & & 10.04 & \\
\hline $\operatorname{Sex}(M / F)$ & $51 / 48$ & & $30 / 29$ & & $21 / 19$ & \\
\hline \multicolumn{7}{|l|}{ FIB-4, $n$} \\
\hline $\mathrm{F} 0-1$ & $36 / 99$ & & $24 / 59$ & & $12 / 40$ & \\
\hline F3-4 & $13 / 99$ & & $5 / 59$ & & $8 / 40$ & \\
\hline \multicolumn{7}{|l|}{ HCV genotype, $n$} \\
\hline 4aw & $82 / 99$ & & $49 / 59$ & & $33 / 40$ & \\
\hline 40 & $9 / 99$ & & $5 / 59$ & & $4 / 40$ & \\
\hline $4 m$ & $5 / 99$ & & $3 / 59$ & & $2 / 40$ & \\
\hline $4 n$ & $3 / 99$ & & $2 / 59$ & & $1 / 40$ & \\
\hline \multicolumn{7}{|l|}{ IL28B genotype, $n(\%)$} \\
\hline $\mathrm{CC}$ & 18/99 (18) & & $11(19)$ & & $7(17)$ & \\
\hline Non-CC & $81 / 99$ (82) & & $48(59)$ & & $33(58)$ & \\
\hline $\operatorname{ALT}(\mathrm{U} / \mathrm{L})$ & 52.93 & 34.99 & 55.23 & 35.91 & 51.60 & 33.60 \\
\hline Mean (SD) & 22.50 & $12.64^{*}$ & 23.36 & $12.97^{*}$ & 21.37 & $21.15^{*}$ \\
\hline AST (U/L) & 55.70 & 36.93 & 55.58 & 37.71 & 56.40 & 35.75 \\
\hline Mean (SD) & 21.62 & $13.58^{*}$ & 21.49 & $13.82^{*}$ & 22.06 & $13.30^{*}$ \\
\hline $\mathrm{HB}(\mathrm{mg} / \mathrm{dl})$ & 14.00 & 10.92 & 13.94 & 10.82 & 14.09 & 11.06 \\
\hline Mean (SD) & 1.87 & $1.01^{*}$ & 1.87 & $0.98^{*}$ & 1.89 & $1.05^{*}$ \\
\hline $\operatorname{RBCs}\left(\times 10^{3}\right)$ & 4.61 & 3.89 & 4.62 & 3.79 & 4.62 & 4.03 \\
\hline Mean (SD) & 0.64 & $0.48^{*}$ & 0.65 & $0.41 *$ & 0.63 & $0.51^{*}$ \\
\hline PLTs $\left(\times 10^{3}\right)$ & 197.83 & 139.22 & 202.48 & 139.65 & 190.85 & 138.57 \\
\hline Mean (SD) & 63.06 & $31.18^{*}$ & 66.75 & $32.89 *$ & 57.19 & $28.82^{*}$ \\
\hline SVR12, $n(\%)$ & & $87 / 99(88)$ & & $55 / 59(93)$ & & $32 / 40(80)$ \\
\hline HCV PCR < 800,000, $n(\%)$ & $20 / 99(20)$ & $20 / 99(20)$ & $3 / 59(5)$ & $3 / 59(5)$ & $6 / 40(15)$ & $6 / 40(15)$ \\
\hline HCV PCR > 800,000, $n(\%)$ & $2 / 99(2)$ & $2 / 99(2)$ & $1 / 59(2)$ & $1 / 59(2)$ & $2 / 40(5)$ & $2 / 40(5)$ \\
\hline
\end{tabular}

HCV - hepatitis C virus, IL28B - interleukin 28, ALT - alanine aminotransferase, AST - aspartate aminotransferase, HB - hemoglobin, RBCS - red cell counts, PLTs - platelets counts, PCR - polymerase chain-reaction, SVR12 - sustained virological response 12 weeks after the end of treatment

*Denotes statistical significance between baseline and SVR12. Data are presented as mean \pm SD or as the number of patients.

has been used in the treatment of GT1, GT3 and GT4 infection, with SVR rates higher than $90 \%[4,15]$. Patients with GT4 infection also had high rates of SVR with a 24-week regimen of SOF plus PegINF/RBV. The SVR rate ( $82 \%$ on intention-to-treat) was reported from the phase II ATOMIC trial, which provided 24 weeks of triple therapy to 11 patients with GT4 infection [10] and achieved $94 \%$ in another clinical study [11]. Further, in line with our results, Salama et al. [16] reported that SOF plus Peg-INF/RBV achieved SVR12 in $91.4 \%$ of Egyptian HCV patients; however, SOF plus RBV achieved SVR12 in 60\%. Otherwise, SOF/RBV when given without PegINF to HCV GT4 infected patients achieved SVR rates of $79 \%$ and $59 \%$ of treatment-naïve and treatment-experienced patients, respectively [17].

The present data obtained from naïve and experienced Egyptians patients revealed that relapses occurred in all treated groups 12 weeks after the treatment cessation. The treatment failure of SOF/PegINF/RBV 
therapy was $12 \%$ ( 8 relapses and 4 null responses). Several studies concluded that usually, treatment failures are related to relapse more than to on-treatment viral breakthrough. Additionally, HCV GT4 indicated low treatment response rates as compared to other HCV genotypes [18]. Lawitz et al. [4] reported that relapsed patients after treatment with SOF plus PegINF/ RBV were mainly patients with cirrhosis, IL28B subtype non-CC and GT1b. Furthermore, the virological response rates are dependent mainly on viral genotypes, ethnicity, and sex [19]. The developing HCV variants reported by several studies were dependent on host- and virus-related factors, the type of the regimens used and the treatment strategy applied [20].

Concerning safety and tolerability profile, the main adverse events recorded during treatment were influenza-like illness, nausea, fatigue, dyspnea, headache, insomnia, hemoglobin decrease, and asthenia. The above adverse events were in line with those reported in several previous studies $[4,11]$. SOF is considered to be well tolerated, but the most common adverse events reported were those related to PegINF/RBV (fatigue, headache, and nausea) [10]. In the present study, there were significant decreases in all hematological parameters: hemoglobin concentration as well as red blood cells, leukocytes, and platelets counts. Our results were in agreement with those of Mostafa et al. [21], who reported that the hematological side effects of PegINF/ RBV regimens included anemia (30.6\%) and leukopenia (9.8\%) in Egyptian patients with HCV GT4 infection.

\section{Conclusions}

The current study revealed that, at the beginning of the interferon-free era, the combination of SOF/ PegINF/RBV could offer an efficacious regimen for treatment of patients with HCV GT4 infection. The recorded efficacy and adverse events indicated the high need for further efforts to minimize the side effects of the current regimen and/or replace PegINF with additional potent DAA(s) to increase SVR12 to $100 \%$.

\section{Disclosure}

The authors report no conflict of interest.

\section{References}

1. Waked I, Doss W, El-Sayed MH, et al. The current and future disease burden of chronic hepatitis $\mathrm{C}$ virus infection in Egypt. Arab J Gastroenterol 2014; 15: 45-52.

2. Anagnostou O, Manolakopoulos S, Bakoyannis G, et al. Genotype $4 \mathrm{HCV}$ infection is difficult to cure with pegylated interferon and ribavirin. Results from a Greek Nationwide Cohort Study. Hippokratia 2014; 18: 57-64.
Table 2. Adverse events (AEs) and laboratory abnormalities of overall patients

\begin{tabular}{ll}
\hline Side effects & Overall patients (99) \\
\hline Any adverse event during treatment, $n$ & 76 \\
\hline Adverse event leading to discontinuation, $n$ & 0 \\
\hline Serious adverse events, $n$ & 3 \\
\hline Adverse events $\geqslant 10 \%$ of patients, $n$ & 48 \\
\hline Fatigue & 39 \\
\hline Headache & 36 \\
\hline Nausea & 27 \\
\hline Dyspnea & 26 \\
\hline Influenza-like illness (fever, myalgia, rigors) & 22 \\
\hline Insomnia & 17 \\
\hline Rash (any type) & 23 \\
\hline Irritability & 11 \\
\hline Diarrhea & \\
\hline Laboratory abnormality, $n$ (\%) & 40 \\
\hline Anemia & 36 \\
\hline Thrombocytopenia & 32 \\
\hline Leukopenia
\end{tabular}

ALT - alanine aminotransferase, AST - aspartate aminotransferase

3. Zoulim F, Liang TJ, Gerbes AL, et al. Hepatitis C virus treatment in the real world: optimising treatment and access to therapies. Gut 2015; 64: 1824-1833.

4. Lawitz E, Mangia A, Wyles D, et al. Sofosbuvir for previously untreated chronic hepatitis C infection. N Engl J Med 2013; 368: 1878-1887.

5. Jacobson IM, Gordon SC, Kowdley KV, et al. Sofosbuvir for hepatitis $\mathrm{C}$ genotype 2 or 3 in patients without treatment options. N Engl J Med 2013; 368: 1867-1877.

6. Bourliere M, Oules V, Ansaldi C, et al. Sofosbuvir as backbone of interferon free treatments. Dig Liver Dis 2014; 46: S212-220.

7. Koff RS. Review article: the efficacy and safety of sofosbuvir, a novel, oral nucleotide NS5B polymerase inhibitor, in the treatment of chronic hepatitis $\mathrm{C}$ virus infection. Aliment Pharmacol Ther 2014; 39: 478-487.

8. Lemoine M, Thursz M. Hepatitis C. A Global Issue: Access to Care and New Therapeutic and Preventive Approaches in Resource-Constrained Areas. Semin Liver Dis 2014; 34: 89-97.

9. EASL. Recommendations on treatment of hepatitis C. 2015. Available at: http://www.easl.eu/research/our-contributions/clinical-practice-guidelines/detail/recommendations-on-treatmentof-hepatitis-c-2015 (Accessed: 4 August 2016).

10. Kowdley KV, Lawitz E, Crespo I, et al. Sofosbuvir with pegylated interferon alfa- $2 \mathrm{a}$ and ribavirin for treatment naïve patients with hepatitis C genotype-1 infection (ATOMIC): an openlabel, randomized, multicenter phase 2 trial. Lancet 2013; 381: 2100-2107.

11. Elsharkawy A, Fouad R, El Akel W. Sofosbuvir-based treatment regimens: real life results of 14409 chronic HCV genotype 4 patients in Egypt. Aliment Pharmacol Ther 2017; 45: 681-687.

12. Sterling RK, Lissen E, Clumeck N, et al. Development of a simple noninvasive index to predict significant fibrosis patients with HIV/HCV co-infection. Hepatology 2005; 43: 1317-1325. 
13. Esmat G, El Kassas M, Hassany M, et al. Optimizing treatment for HCV genotype 4: PEG-IFN alfa 2a vs. PEG-IFN alfa 2b; the debate continues. Liver Int 2014; 34: 24-28.

14. Rodriguez-Torres M, Lawitz E, Kowdley KV, et al. Sofosbuvir (GS-7977) plus peg-interferon/ribavirin in treatment-naïve patients with HCV genotype 1: a randomized, 28-day, dose-ranging trial. J Hepatol 2013; 58: 663-668.

15. Foster GR, Pianko S, Cooper C, et al. Sofosbuvir + Peg-interferon/Ribavirin for 12 weeks vs Sofosbuvir + Ribavirin for 16 or 24 weeks in Genotype $3 \mathrm{HCV}$ infected patients and treatment-experienced cirrhotic patients with genotype $2 \mathrm{HCV}$ : The BOSON study. J Hepatol 2015; 62: S259-S260.

16. Salama H, Zekri AR, Medhat E, et al. Effect of Sofosbuvir, Brand Drug (Sovaldi) versus generic (MPI Viropack) in treating chronic HCV genotype 4 infection among Egyptian patients. EC Gastroenterology and Digestive System 2016; 1.2: 56-61.

17. Ruane PJ, Ain D, Stryker R, et al. Sofosbuvir plus ribavirin for the treatment of chronic genotype 4 hepatitis $\mathrm{C}$ virus infection in patients of Egyptian ancestry. J Hepatol 2015; 62: 1040-1046.

18. Riad SE, El-Ekiaby N, Mekky RY, et al. Expression signature of microRNA-155 in hepatitis $\mathrm{C}$ virus genotype 4 infection. Biomed Rep 2015; 3: 93-97.

19. Kau A, Vermehren J, Sarrazin C. Treatment predictors of a sustained virologic response in hepatitis B and C. J Hepatol 2008; 49: 634-635.

20. Buti M, Esteban R. Management of direct antiviral agent failures. Clin Mol Hepatol 2016; 22: 432-438.

21. Lashin AH, Shaheen YA, Metwally MA, et al. Incidence and predictors of hematological side effects in chronic HCV Egyptian patients treated with pegylated interferon and ribavirin. Indian J Gastroenterol 2013; 32: 316-323. 